\title{
Hubungan Kecerdasan Emosi dengan Anxiety Reduction pada Mahasiswa Fakultas Farmasi Institut Kesehatan Helvetia
}

\section{The Relationship Between Emotional Intelligence And Anxiety Reduction In Pharmaceutical Students Of The IKH Medan}

\author{
Ernida Marietha Manurung \& Tilik Adil Dachi \\ Program Studi Psikologi, Fakultas Farmasi dan Kesehatan, \\ Institut Kesehatan Helvetia, Indonesia
}

Diterima: Agustus 2019; Disetujui: Desember 2019; Dipublish: Desember 2019

*Coresponding Email: ernidamarietha@gmail.com

\section{Abstrak}

Penelitian ini bertujuan mengetahui hubungan kecerdasan emosi dengan anxiety reduction pada mahasiswa Fakultas Farmasi Institut Kesehatan Helvetia Medan Tahun Ajaran 2016/2017. Pendekatan yang digunakan dalam penelitian ini adalah pendekatan kuantitatif. Alat ukur yang digunakan berupa skala kecerdasan emosi yang disusun berdasarkan teori kecerdasan emosi oleh Goelman yang memiliki 30 iaitem dan skala anxiety reduction yang disusun berdasarkan teori Conroy memiliki 30 aitem. Jumlah sampel dalam penelitian ini adalah 80 mahasiswa Fakultas Farmasi. Metode analisis data yang digunakan dalam penelitian ini adalah korelasi pearson Product Moment dengan korelasi $r=0,649$ dengan signifikan $\mathrm{p}=0.000$ berarti $(\mathrm{p}<0.01)$. Hasil analisis data menunjukkan bahwa ada hubungan negatif yang signifikan antara kecerdasan emosi dengan anxiety reduction mahasiswa. Hal ini menunjukkan bahwa semakin tinggi kecerdasan emosi yang dimiliki oleh mahasiswa maka semakin mudah untuk menurunkan kecemasan (anxiety reduction), dan semakin rendah kecerdasan emosi yang dimiliki mahasiswa maka akan semakin sulit untuk menurunkan kecemasan (anxiety reduction).

Kata Kunci: Kecerdasan Emosi, Anxiety Reduction

\begin{abstract}
This study aims to determine the relationship of emotional intelligence with anxiety reduction in students of the Faculty of Pharmacy, Institut Kesehatan Helvetia Medan 2016/2017. This study used quantitative approach. Measuring instruments used in the form of emotional intelligence scales are based on the theory of emotional intelligence by Goleman who has 30 items and anxiety reduction scales that are based on Conroy's theory have 30 items. The samples of this study were 80 students of the Faculty of Pharmacy, Institut Kesehatan Helvetia. The data analysis method used in this study is the Pearson Product Moment correlation with the correlation $r=-0,649$, with a significant $p=0,000$ means $(p<0.01)$. The results of the research showed that there was negative but significant correlation between emotional intelligence and student anxiety reduction. This shows that the higher emotional intelligence possessed by students, the easier it is to anxiety reduction, and the lower the emotional intelligence possessed by students, the more difficult it is to anxiety reduction.
\end{abstract}

Keywords: Emotional Intelligence, Anxiety Reduction

How to Cite: Manurung, E.M \& Dachi, T.A (2019). Hubungan Kecerdasan Emosi dengan Anxiety Reduction Pada Mahasiswa Fakultas Farmasi Institut Kesehatan Helvetia. Journal of Education, Humaniora and Social Sciences (JEHSS). 2 (2): 195-202. 


\section{PENDAHULUAN}

Pada umumnya manusia berupaya untuk melakukan proses adaptasi dalam menjalankan tugas-tugas masa perkembangan. Kadangkala pada setiap prosesnya manusia menghadapi hambatan ataupun persoalan dari berbagai aspek. Hal ini dapat menimbulkan emosi negatif bahkan tekanan psikologis dalam diri seseorang. Emosi negatif yang muncul karena menghadapi konflik, rasa tegang, perasaan gagal dan tidak aman akan menimbulkan kecemasan (Whitehead dalam Anggawira, 2013). Kecemasan merupakan ancaman besar bagi semua manusia pada setiap fase perkembangannya. Keadaan ini dapat menjadi penghalang utama dalam mencapai keberhasilan hidup.

Mahasiswa sebagai pelajar juga mengalami kecemasan. Salah satunya dalam menjalankan proses pembelajaran di bangku kuliah. Belajar merupakan bagian dari tugas masa perkembangan periode dewasa awal. Pendidikan dianggap sebagai bekal untuk masa depan. Mahasiswa berjuang untuk menyelesaikan tugas-tugas kuliah, lulus setiap mata kuliah, nilai IPK yang memuaskan dan menjadi seorang sarjana yang siap bekerja. Secara umum kondisi ini dapat menyebabkan stres dan cemas. Hal ini sangat berkaitan dengan persoalan tugas kuliah, praktikum, Nilai Indeks Prestasi (IPK) yang kurang memuaskan.

Selain itu kegagalan dalam tugas akhir, lingkungan yang tidak kondusif, kelelahan dan juga kejenuhan kuliah merupakan bagian di dalamnya. Keadaan tersebut menimbulkan tekanan psikologis secara interpersonal dalam memahami keberhasilan belajar. Persoalan kecemasan secara personal memiliki interpretasi yang berbeda-beda. Ada mahasiswa yang dapat dengan mudah memahami apa yang membuat prestasi belajarnya rendah dan mengolah kecemasan sebagai usaha untuk perbaikan diri. Namun untuk mahasiswa yang pasif, kecemasan dapat mengurangi produktivitas mereka untuk melakukan usaha. Pemahaman mereka tentang keberhasilan belajar akan semakin memburuk.

Pines dan Aronson (dalam Santrok, 2003) menyampaikan bahwa kecemasan yang dialami seringkali akan menjadikan individu merasa tidak berdaya dan tidak memiliki harapan yang akan membuat individu tersebut merasa sangat kelelahan secara fisik dan emosional. Kelelahan ini dapat berakibat pada berkurangnya ketertarikan mahasiswa 
dalam mengikuti proses pembelajaran hingga pada tahap tugas akhir. Selanjutnya Priest (dalam Namora Lumongga Lubis, 2009) menyatakan bahwa salah satu defenisi kecemasan adalah takut akan kelemahan. Kecemasan adalah perasaan yang individu alami ketika berpikir tentang sesuatu tidak menyenangkan yang akan terjadi. Kata-kata lain untuk menggambarkan kecemasan yaitu merasakan "ketakutan", "tidak tentu", "bingung" atau merasa takut akan kesalahan.

Penjelasan mengenai kecemasan dan gejalanya sangat penting diketahui oleh setiap mahasiswa. Kecemasan akan menjadikan segala sesuatu sengsara. Perasaan cemas dan khawatir mempengaruhi berbagai aspek dalam hidup mahasiswa. Beberapa mahasiswa kadang menyikapi prestasi (nilai hasil) belajar rendah ataupun hambatan dalam tugas akhir sebagai permasalahan dalam hidupnya. Ia akan malu karena hasil belajar yang buruk maupun karena merasa tidak percaya diri dengan persiapan yang dimilikinya. Keadaan tersebut seharusnya membuat mahasiwa melakukan usaha-usaha untuk menguasai, meredakan atau menghilangkan berbagai tekanan yang dialaminya.

Sebenarnya emosi negatif maupun kecemasan memberikan sinyal kepada kita untuk waspada, namun kewaspadaan yang berlebihan tanpa tindakan bisa berakibat lebih buruk. Untuk itu dibutuhkan kemampuan pengaturan diri agar mampu mengendalikan emosi dengan menempatkannya ke dalam hal positif serta mampu menghibur diri sendiri sehingga emosi-emosi negatif tersebut tidak akan berlanjut menjadi rasa cemas yang mengganggu kondisi psikologis mahasiswa. Kondisi tersebut memperjelas sejauhmana kecerdasan emosi mampu mengendalikan atau menurunkan kecemasan seseorang.

Menurut Goleman (2009) kecerdasan emosi adalah ketika seseorang mampu memahami dan mengenali perasaan mereka sendiri serta mampu mengenali perasaan orang lain, mampu memotivasi diri sendiri serta mampu mengenali perasaan orang lain, mampu memotivasi diri sendiri dan memiliki pengelolaan emosi yang baik dan interaksi yang baik dengan orang lain. Dikatakan mampu mengendalikan emosi apabila mengetahui waktu yang tepat dalam mengambil suatu tindakan dan tindakan yang tepat pada situasi tertentu. 
Menurut Cooper \& Sawaf (dalam Djuwarijah, 2002), telah dibuktikan dari berbagai penelitian bahwa keberhasilan masa depan seseorang banyak disumbangkan dari kecerdasan emosional (EQ) yang dimiliki dibandingkan dengan kecerdasan intelektual (IQ). Kecerdasan emosi adalah suatu fenomena manusiawi secara mendasar ada dalam diri manusia. Artinya seseorang dapat mencapai keberhasilan hidup semaksimal mungkin melalui kecerdasan emosi, karena itu kecerdasan emosi sangat diperlukan oleh mahasiswa. Hasil penelitian Gottman (dalam Djuwarijah, 2002) bahwa anak-anak yang bisa mengenali dan menguasai emosinya lebih percaya diri, lebih baik prestasinya dan akan menjadi orang dewasa yang mampu mengendalikan emosinya.

Ketika seseorang memiliki kecerdasan emosi yang tinggi maka ia akan mampu menghindari berbagai tindakan yang dapat merugikan diri sendiri maupun orang lain seperti tindakan agresif ataupun verbal dan emosi negatif seperti mudah marah, mudah tersinggung (Goleman, 2000). Peran kecerdasan emosi sangat penting bagi setiap mahasiswa, karena dengan bekal kecerdasan akademis saja belum cukup untuk merencanakan sebuah kesuksesan.

Mahasiswa yang memiliki kecerdasan emosi yang tinggi akan lebih mudah untuk mengelola masalahnya, mampu memadukan tujuan yang ingin diraih dengan emosi yang positif, membayangkan pencapaian tujuan dengan hati yang gembira serta mempunyai hubungan sosial yang baik dengan orang lain. Kemampuan ini secara bertahap akan menurunkan kecemasan (anxiety reduction). Namun pada mahasiswa yang memiliki kecerdasan emosi yang rendah akan menyebabkan ketidakefekktivan dalam berusaha.

Hal ini dibuktikan oleh Nuraini (dalam Sella\&Libbie, 2014) melalui penelitiannya menjelaskan bahwa kecerdasan emosi diperlukan oleh seseorang ketika menghadapi suatu masalah yang dapat menimbulkan tekanan atau kecemasan. Seseorang yang memiliki kecerdasan emosi yang baik akan mampu mengatur emosi, mengolah emosi sehingga dapat meminimalisir perasaan cemas yang muncul dan menjadi suatu kekuatan yang lebih positif.

Berdasarkan uraian di atas peneliti melihat masalah kecemasan menjadi persoalan yang penting untuk diamati. Sejauhmana kecerdasan emosi mampu mengurangi kecemasannya (anxiety reduction) dalam melaksanakan pembelajaran di bangku kuliah. 
Seorang mahasiswa harus mampu mengelola kecemasan dengan baik dan menjadikan kecemasan sebagai motivasi dalam mencapai tujuan. Untuk itu peneliti akan melakukan penelitian dengan judul "Hubungan Antara Kecerdasan Emosi dengan Anxiety Reduction Pada Mahasiswa Fakultas Farmasi Institut Kesehatan Helvetia Tahun Ajaran 2016/2017".

\section{METODE PENELITIAN}

Metode penelitian ini menggunakan pendekatan kuantitatif korelasional. Penelitian ini digunakan untuk meneliti sejauh mana hubungan antara kedua variabel atau lebih (Sugiyono, 2008). Sampel adalah sejumlah subjek yang merupakan bagian dari populasi yang mempunyai sifat yang sama (Hadi, 2000). Teknik pengambilan sampel yang digunakan adalah purposive sampling dengan melakukan pertimbangan-pertimbangan tertentu dalam pengambilan sampelnya. Sampel yang digunakan sebanyak 80 orang. Metode pengumpulan data menggunakan likert dengan 4 pilihan jawaban. Skala yang digunakan yaitu skala kecerdasan emosi berdasarkan komponen-komponen kecerdasan emosi yang dikemukakan oleh (Goleman, 2001) dan skala anxiety reduction berdasarkan aspek-aspek ketakutan akan kegagalan berdasarkan teori Conroy (dalam Pujiono, 2015). Analisis data menggunakan SPSS versi 18.

\section{HASIL DAN PEMBAHASAN}

Tabel 1. Korelasi Antara Kecerdasan Emosi dengan Anxiety Reduction

\begin{tabular}{ccc} 
Analisis & Pearson Correlation & Signifikan $(\mathrm{p})$ \\
\hline Korelasi & 0,649 & 0.000
\end{tabular}

Hasil penelitian kepada 80 mahasiswa Fakultas Farmasi Institut Kesehatan Helvetia dalam penelitian ini menunjukkan ada hubungan negatif antara kecerdasan emosi dengan anxiety reduction. Hal ini dapat diperhatian dalam tabel 1 berdasarkan hasil analisis korelasi antara kecerdasan emosi dengan anxiety reduction sebesar 0,649 dengan sig. sebesar $0.000(\mathrm{p}<0.05)$. Hal ini menunjukkan bahwa adanya korelasi negatif antara kecerdasan emosi dengan anxiety reduction sehingga dikategorikan hubungan yang cukup kuat (Priyanto, 2010). Dari hasil perhitungan tersebut, maka hipotesis yang 
diajukan dalam penelitian ini menunjukkan ada hubungan negatif antara kecerdasan emosi dengan anxiety reduction.

Selanjutnya nilai koefisien determinan $\left(\mathrm{R}^{2}\right)$ dari hubungan variabel bebas dengan variabel terikat dalam tabel 2 dibawah ini sebesar $\mathrm{R}^{2}=0,421$. Hal ini menunjukkan bahwa penurunan kecemasan (anxiety reduction) dipengaruhi oleh kecerdasan emosi sebesar $42,1 \%$ dan selebihnya 57,9\% dipengaruhi oleh faktor-faktor lainnya yang pada penelitian ini tidak diteliti. Nilai yang cukup besar membuktikan bahwa semakin tinggi kecerdasan emosi maka semakin mudah untuk menurunkan kecemasan, sebaliknya semakin rendah kecerdasan emosi yang dimiliki maka semakin sulit untuk menurunkan kecemasan.

Kemampuan dalam menggunakan emosi secara cerdas dan menggunakannya sebagai pemandu perilaku dan pemikiran merupakan defenisi kecerdasan emosional yang tepat (Weisinger, 2006). Artinya seorang mahasiswa harus mampu menggunakan emosi secara cerdas sehingga ia mampu membedakan dan menanggapi dengan tepat suasana hati, temperamen, motivasi dan hasrat orang lain.

Tabel 2. Hasil Analisis Product Moment

\begin{tabular}{llllll}
\hline Statistik & Koefisien $\mathrm{r}_{\mathbf{x y}}$ & Koef. Det $\left(\mathrm{r}^{2}\right)$ & $\mathrm{P}$ & $\mathrm{BE} \%$ & Keterangan \\
\hline $\mathrm{X}-\mathrm{Y}$ & 0,649 & $\mathbf{0 , 4 2 1}$ & 0,000 & $42,1 \%$ & Signifikansi
\end{tabular}

Hal ini sejalan dengan pendapat Gottman (dalam Djuwarijah, 2002), yang menyatakan bahwa kecerdasan emosi digambarkan dengan anak-anak yang bisa mengenali dan menguasai emosinya, lebih percaya diri, lebih baik prestasinya dan akan menjadi orang dewasa yang mampu mengendalikan emosinya. Selanjutnya Goleman (2000) menyatakan bahwa seseorang yang memiliki kecerdasan emosi yang tinggi akan mampu bertahan menghadapi frustasi, mengatur suasana hati, menjaga agar beban stres tidak melumpuhkan kemampuan berpikir dan mampu mengendalikan kinerja yang optimal.

\section{SIMPULAN}

Kesimpulan dari penelitian ini dapat dilihat dari hasil analisis Product Moment yang diketahui bahwa terdapat hubungan negatif antara kecerdasan emosi dengan anxiety reduction pada mahasiswa Fakultas Farmasi dengan $r_{\mathbf{x y}}=-0,649$ dan $p=0,000<0,010$, artinya semakin tinggi kecerdasan emosi yang dimiliki mahasiswa maka akan semakin 
mudah menurunkan kecemasan (anxiety reduction), dan semakin rendah kecerdasan emosi akan semakin sulit menurunkan kecemasan (anxiety reduction). Maka hipotesis yang diajukan diterima, yaitu ada hubungan antara kecerdasan emosi dengan penurunan kecemasan anxiety reduction).

\section{UCAPAN TERIMAKASIH}

Kepada pihak yang banyak membantu dan mendukung peneliti dalam menyelesaikan penelitian ini antara lain: Tuhan Yang Maha Esa yang telah memberikan kesehatan, kekuatan dan kemampuan kepada peneliti dalam menyelesaikan penelitian ini; Yayasan Institut Kesehatan Helvetia Medan sebagai lembaga pemberi dana kepada peneliti dalam menyelesaikan penelitian ini; Keluarga saya yang telah memberi dukungan dan perhatian terbaik dalam penelitian ini dan Teman-teman program studi Psikologi Institut Kesehatan Helvetia

\section{DAFTAR PUSTAKA}

Andrian, Doni. (2017). Mengelola Kecemasan Siswa Dalam Pembelajaran Matematika. Medan. Seminar Nasional Matematika UNIMED.

Anggawira, A. (2013). Terapi eye movement disentisization reprocesing (emdr) untuk menurunkan kecemasan dan depresi pada narapidana kasus penyalahgunaan napza. Tesis (tidak diterbitkan). Yogyakarta: Fakultas Psikologi \& Ilmu Sosial Budaya Universitas Islam Indonesia.

Azwar, S. 2007. Metode Penelitian. Yogyakarta: Pustaka Pelajar

Chaplin, J.P, (2006). Kamus Lengkap Psikologi, Jakarta: Rineke Cipta

Djuwarijah. (2002). Hubungan Antara Kecerdasan Emosi Dengan Agresivitas Remaja. Journal of Psychology. Psikologika Nomor 13 Tahun VII

Goleman, D. (2000). Emotional Intelligence: Kecerdasan Emosionaal Mengapa EI Lebih Penting Daripada IQ. Jakarta: PT. Gramedia Pustaka Utama

Goleman, D. (2001). Kecerdasan Emosi Untuk Mencapai Puncak Prestasi. Jakarta: Gramedia Pustaka Umum Goleman, D. (2009). Emotional Intelligence: Kecerdasan Emosionaal Mengapa EI Lebih Penting Daripada IQ. Jakarta: PT. Gramedia Pustaka Utama

Goleman, D. 1996. Kecerdasan Emosional (Terjemahan: Hermaya). Jakarta: Garmesia Pustaka Utama

Gunarsa \& Gunarsa (2000). Psikologi Praktis: anak, remaja, dan keluarga. Jakarta: Gunung Mulia

Hadi, S, 2000. Metodologi Research. Yogyakarta: Penerbit Andi Yogyakarta

Kaplan, H.L, Sadock, B.J dan Grebb, J.A. 2006. Sinopsis Psikiatri, Ilmu Pengetahuan Perilaku Psikiatri Klinis. Edisi 7. Jilid II. Jakarta: Binaputra Aksara

Kartono. K. (2006). Kenakalan Remaja. Jakarta: Raja Grafindo Parsada.

Leonard. (2008). Pengaruh Konsep Diri, Sikap Siswa Pada Matematika dan Kecemasan Siswa Terhadap Hasil Belajar Matematika (Survei Pada SMP di Wilayah DKI Jakarta), Universitas Indraprasta PGRI.

Namora Lumongga Lubis. 2009. Depresi: Tinjauan Psikologis. Jakarta: Kencana Prenada Media Group Pujiono, C.H. (2015). Tingkat Ketakutan Akan Kegagalan Mahasiswa Angkatan 2011 Jurusan Psikologi Dengan IPK Kurang Dari 2,75 Dalam Mengahadapi Persaingan Kerja. Skripsi Semarang Fakultas Ilmu Pendidikan Universitas Negeri Semarang 
Salovey, P., \& Mayer, J.D. (1990). Emotional Intelligence. Baywood Publishing Co,inc. Diunduh di http://www.unh.edu/emotional_intelligence/EIAassets/EmotionalIntelligenceProper/EI1990\%20E motional\%20Intelligence.pdf pada 20 Feb 2018

Santrock, J.W. (2003). Perkembangan Remaja. Jakarta: Erlangga

Sella, I.M \& Libbie A. (2014). Hubungan Kecerdasan Emosi Dengan Kecemasan Menghadapi Masa Pembebasan Pada Narapidana. Jurnal Psikologi Integratif, Vol. 2, No. 2

Stuart \& Sundeen. (1998). Buku Saku Keperawatan Jiwa. (Alih Bahasa) Achir Yani. Hamid. Edisi 3. Jakarta: EGC

Sugiyono. (1997). Statistika Untuk Penelitian. Bandung: Alfabeta.

Sugiyono. (2008). Metode Penelitian Kuantitatif, dan R\&D. Bandung: CV Alfabeta

Weisinger, H., (2006), Emosional Intelligence at Work: Pemandu Pikiran dan Perilaku Anda Untuk Meraih Kesuksesan, PT Bhuana Ilmu Populer, Jakarta. 